\title{
The Truth behind the Fallen Leaves: Untold Stories of Unsuccessful LET Examinees
}

\author{
Joseph Dave Pregoner
}

\author{
Affiliation: \\ Joseph Dave M. Pregoner \\ Research Teacher \\ Basic Education \\ University of Immaculate Conception \\ Annex Campus \\ Bonifacio St., Davao City \\ (082) 2271573 \\ (082) 2273794 \\ jdpuic@gmail.com
}

\begin{abstract}
This case study was conducted to disentangle the stories of unsuccessful LET examinees, their responses to failure, and their perspectives of the factors that contributed to their failure. The results demonstrate five themes related to the failure experience. Factors related to the physical environment, psychological well-being, and preparedness influenced the performance of the examinees. Contributory factors to failure provided several implications to teacher education practice. Educators have a responsibility to identify, inform, and intervene with students who are at high risk of failing the LET, and this responsibility could be executed capably. However, the role should be extended beyond graduation. The responsibility to help graduates transition from failure to licensure is the final step of successful undergraduate teacher education.
\end{abstract}

Keywords: case study; LET; failure 


\section{Chapter 1}

\section{Introduction}

A teacher is a hero. This is what we usually describe our teachers in every teacher's day. They are the one who will guide us and mold us to the best version of ourselves. They will share knowledge and wisdom to us which we can use in the future. They equip us with the necessary skills, knowledge, and attitude to face the cruel world. They honed us to be globally competitive and shared their expertise. They are the people whom we can share our secrets, disappointments and trials in life. If we fall down twice, they will help us stand up thrice. They are our second parents. In fact, teaching profession is usually equated to "noble profession".

One of the requirements to become a teacher is to have content and pedagogical knowledge (Schulman, 1986); this is the type of knowledge which is unique to teacher. This means that the teacher should have the content knowledge which refers to the mastery of subject and pedagogical knowledge which refers to the general knowledge of instructional methods. But, apart from these things, how can one become a professional teacher? According to the Department of Education (DepEd) one must be a graduate of bachelor of education either secondary or elementary. Another qualification is to pass the board examination which is a requirement according to the Republic Act No. 7836 or also known as "Philippine Teachers Professionalization Act of 1994" which requires all aspirant teachers to take and pass the licensure examination for teachers to strengthen the supervision and regulation in teaching profession. The state recognizes the vital role of teachers in nation-building and development through a responsible and literate citizenry. Towards this end the State shall ensure and promote quality education by proper supervision and regulation of the licensure examination and 
professionalization of the practice of the teaching profession (PRC). But what if a graduate of bachelor of secondary/elementary education failed in the licensure examination for teacher? This research aims to find out what is the main reason why they failed.

The Board for Professional Teachers (BPT) and the Professional Regulation Commission (PRC) announced last November 28, 2016 that 23,378 elementary teachers out of 77,466 examinees $(30.18 \%)$ and 31,334 secondary teachers out of 92,754 examinees $(33.78 \%)$ successfully passed the Licensure Examination for Teachers (L.E.T.) given last November 29, 2016. It is also reported that 21,896 are first timers and 1,482 are repeaters for the elementary teachers. For the secondary takers, 28,957 passers are first timers and 2,377 are repeaters (PRC Board, 2016). It is evident that the national passing rate is not that high. While the University of Mindanao had 66 repeaters (PRC Board, 2016) and out of 66 repeaters only 3 repeaters passed (PRC Board, 2016) and the remaining 63 repeaters failed which means The University of Mindanao only had $4.55 \%$ (PRC Board, 2016) passing rate in terms of the repeaters . This study aims to answer the reasons why some let takers failed to pass for the licensure examination.

\section{Purpose of the Study}

To pass the licensure examination is one of the stepping stones to become a professional teacher. Indeed, if they cannot pass the standardized exam, they cannot consider themselves a successful teacher. The purpose of this study is to distinguish the reasons why some takers of the licensure examination for teachers failed. The researchers would like to know respondents' strategies and preparations before they took the exam. In addition, the researchers want to know their struggles in taking the 
examination. Furthermore, the researchers would like to find out if their performance way back in college has a significant impact in their performance in taking the examination. Finally, the researchers want to know the stories behind their failure.

\section{Research Question}

1. What do you think were the major reasons or factors why you failed the Licensure Examination for Teachers?

The answers in this question will be provided by the 3 Licensure Examination for Teachers takers who took the exam and failed. Several factors affecting the results of their examination include misleading questions (Moses, 2013). Another factor is poor time management skills and procrastination (Thames, 2012). Lack of motivation is another factor which Ojumu (2016) also found out. Omisore (2015) also pointed out that not reading "wide and deep" enough is another factor in failing examination. Hence, he also stressed out that not following the trend of examination papers is another factor (Omisore, 2015). However, the "story" why the takers of the LET failed is missing. In this research, every participant has a unique story to tell.

\section{Significance of the Study}

Passing the licensure examination for teachers is one of the prerequisites in becoming a professional teacher. This is a mandatory standardized test according to the Republic Act No.7836 in order to strengthen the supervision and regulation in teaching profession (PRC). If you failed, you will also fail the chance of being a licensed teacher. The purpose of this study is to develop an in-depth description and analysis about some examinees of Licensure Examination for Teachers who took the examination for the third time and still failed. 


\section{Scope and Limitation of the study}

This study is focused on the Licensure Examination for Teachers examinees who failed. We have three (3) selected takers who will be interviewed and will become the subject of our case study who will be liable for claiming our research endeavor. Furthermore, the answers and outcomes will be consolidated, compared, analyzed, and broken down, which will focus on the shared elements of every examinee. The replies will be viewed to determine the common denominator.

\section{Definition of Terms}

The following terms were used in this research:

Licensure Examination (RA7836) : is an act in order to strengthen the supervision and regulation of the teaching profession and teaching practice in the Philippines (PRC)

Teaching: it refers to the profession concerned with the classroom instruction at the secondary and elementary levels in accordance with the curriculum which is prescribed by the Department of Education (PRC)

Teachers: it refers to the professional who is in teaching career who implements the curriculum, performs supervision and administrative functions in school (PRC) 


\section{Review of Related Literature}

Presented in this chapter is a synthesis of research that supports the study about the failure of The University of Mindanao education students in the Licensure Examination for Teachers. Included in this chapter are the causes why students failed in their examinations.

The main concern of the teacher education is the preparation of globally competitive teachers who are competent enough and who can permeate with the ideals, aspirations, and traditions of Philippine life and sufficiently equipped with the pedagogical knowledge and skills (CHED Memorandum Order No. 11, 1999). Whatever skills acquired or gained by the students in all their subjects are always assessed and evaluated, expressed through their grades and holistically learned as academic performances.

Teaching performance is connected to 'effectiveness' (Haper, Candice and de Jong, 2004). In terms of the Philippine educational setting, part of having a quality teaching performance is passing the Licensure Examination for Teachers (LET). It is mandated by the Philippine government in 1996 (Professional Regulation Commission website), the Licensure Examination for Teachers (LET) is a standard test measure administered by the PRC to determine who among the teacher education graduates courses are technically and academically fit to be considered or called 'professional teachers.' Due to the demand of the examination to place the graduates as licensed and non licensed, the examination covers the component areas of education: Professional Education, General Education and Major Field of Concentration or Specialization. As stated by Ramos (2009), the results of the LET could be taken as a valid predictor of 'teaching competence.' Studies made on the teacher licensure examination used in the 
country in the early period, the Professional Board Examination for Teachers (PBET), also emphasized how the licensure examination could be a basis of the teaching performance of teachers.

According to Ditan (2008), the word quality is significant especially in the field of education and it merely suggests the highest standard of teaching in an institution. The foundation of having quality education is upon the abilities of an institution to produce quality professionals. The qualification to become a professional individual is usually proved by passing Professional Regulation Commission (PRC) board examination.

The Professional Regulation Commission (PRC) is the agency of the National Government charge with the regulation and licensing profession in the Philippines. The said agency are committed to fullest, to protect, the integrity of the licensure examination and to change the public perception from that of doubt and despair to trust and confidence in the licensure examination system.(PRC, 2006).

As cited by Caringal (2001), passing the licensure examination given by the Professional Regulation Commission (PRC) is one of the greatest achievements in one's career. This examination is intended to prove the graduates' progress, knowledge, qualification and skills in a particular profession. It needs a hard time to study, to have patience, self-discipline, determination and this will not be possible without prayers, encouragement and support.

As discussed by Alipio (2020), the subjectivity of their academic performance evaluation has diminished in recent years, but it has not been totally excluded. It may not be achievable to fully remove subjectivity from the current evaluation methods. 
Standardized testing is the best responded to by students who excel in mathematics, reading, and test-taking, a skill or performance that is not itself indicative of academic worth. However, as cited by Merrigan (2000) he discussed that through standardized tests are indicators for evaluating academic progress of the students. In addition, the Licensure Examination designed for Teachers is an example of a standardized test and once passed the examination will serve as passport for graduates of Teacher Education Institution (TEI) to land in a teaching career and may enjoy the essence of being a teacher in schools (Rancodo, 2012).

\section{Academic Performance in the Licensure Examination}

Teachers have long been looking for the performance of achievement for students as they enter college or tertiary because unsuccessful students waste personal and social time and resources of the educational institution (Buckingham and Clifton, 2001). Furthermore, students who can recognized as "at risk" for failure early in their academic careers can be targeted for interventions in order for them to learn or to increase the likelihood of success.

Some schools and universities in the Philippines have experienced the closure of some program off springs ordered by the Commission on Higher Education (CHED) because of poor performance of their takers in the licensure examinations. However, college of education in Eastern Visayas State University is also experiencing low percentage of passers on Licensure Examination for Teachers yet if this findings will continuously resulting the same manner, thus this course program will be ended. Most of them do not meet the national passing rate for consecutive years or cannot even produce board passers in the licensure examinations for teachers. Moreover, this 
problem may be making plans and formulate solutions.

\section{Causes of Failing the Examination}

According to Achebe (2001), feeling feared before or during an examination is normal and it can, in certain limits, build up the student's performance. Without any encouragement or fear of failure to perform well on the test, a student is unlikely to put sufficient effort into preparation or be adequately motivated when actually taking the test. Therefore he may not perform well to his fullest potential. By denying a test importance the student may take an avoidant approach to the test, failing arrive for the test itself, and failing to prepare adequately or missing preparation lessons. Furthermore, if before or during a test the student's level of fear is above the proper level, he may also fail to express his true abilities and capabilities. Under these situation, fear of the actual test may disrupt their preparation and cause sufficient anxiety during the test to impair performance. Fear causes the amygdala, one region of the brain, to put the body on alert and alive, quickly shutting down higher-order thinking skills, longterm memory, and our capacity to perform a certain task. As a result, sometimes students happen to know the answers after the test, but not while taking it.

As reported by Duley et al. advised that fear of failure represents an avoidanceoriented success motive that energizes achievement behavior to avoid demonstration of inadequacy. However, when a student avoids a learning situation, fear and other negative feelings can be strengthened.

As stated by Thompson, that failure-avoidant strategies are often recognized to students. These strategies include self handicapping, self-worth protection, procrastination, impostor fears and defensive pessimism. The term self-worth protection means, that students often avoid continue on a learning task because they 
fear that failure could reduce their self-esteem. A similar method is self-handicapping. Some learners claim to have a handicap in order for them to avoid responsibility for a potential failure. They may even aggravate injure to themselves before an important test. Therefore, in case of their failure it is not accurate whether their failure is due to low ability or due to the inconvenience provoked by their injury. Learners being impatient of their failure may use the strategy of procrastination, meaning that they may delay undertaking a learning task. Impostor fears refer to learners that are frightened of people losing respect for them because of low achievements. The test taker fears the possibility that other key people (e.g., peers, teachers, or parents) will diminish them for poor test results. Once assigned with a learning task they deeply stressed or pressured, resulting in emotional exhaustion and anxiety. Defensive pessimism it is a strategy which refers to students that purposely hold low expectations from the result of their learning efforts. While this strategy helps learners cope with anxiety, it is also emotionally draining. Although failure avoidant strategies are differentiated to each other, all of strategies include fear of failure and avoidance of rigorous effort concerning a learning task. As stated by Thompson, they are motivated by the same need to protect a low or vulnerable self-esteem.

\section{Related Studies}

Mock board examination builds up student self confidence and that the "mock grade" given enables him/her to plan his/her remaining studies accordingly ("Examination Entry"). According to Montemayor et al (2009), mock board examinations can give information to student and administrators on whether or not the students are ready to take an external examination for teachers, they provide 
information on students' areas in terms of their strengths and weaknesses, and can serve as practice in taking the tests under full examination conditions.

According to Geemiz (2011), a Mock Board Examination is a simulation for the actual board examination. Any school or organization can conduct a mock board exam without notice and consultation with Professional Regulation Commission (PRC). Moreover, it is a helpful tool as a learning activity to help students gain knowledge with the question formats and the performance needed as a whole. This simulation motivates the students to prepare and to study them well for the national board experience. It can be a effective and valid addition to board preparation activities. Some graduating education students who passed the mock board examination unfortunately failed in the actual board examination because they underestimate the board examination itself.

According to study of Riney et al (2006), they found out that respondents gained positive impact performance in the mock board examination. It has been suggested to continually conduct comprehensive tests or mock board examinations to education graduates before taking the licensure examination for teachers to increase their probability in passing the board examination. On the other hand, higher education institutions are presently giving much attention to licensure examination performance of their graduates. Methodical review materials are carefully prepared and the best reviewers are selected. Additionally, majority of the institutions conducting the review focus less on the result of the mock board examination. There were no feedback and support given to the reviewers after taking the said exam.

As stated by Taren et.al (2004), they concluded that the results of the mock board examination along with general weighted average in the academic performance of the graduates are considered important to the response quality in the licensure 
examination for teacher's performance. Meanwhile, using PART and JRip classifiers, a reviewee will obtain a mock board rating lower than $34 \%$ of the total points. Other than these particular rules, the reviewee is predicted to pass the licensure examination for teachers. These models can help to the reviewer as it distinguishes students who needed special review assistance and eventually increase the passing rate of the schools.

In the study conducted by Castro (2006), he mentioned that the present educational system is confronted with teacher's applicants who are graduates of courses from certain colleges or universities but do not seem to have equipped themselves with the necessary skills in terms of their communication and teaching competencies. This statement is supported by the dismal performance of the takers of the licensure examination for teachers.

It is not only the school that may benefit from the results of the licensure examination but also the graduates. Results of their performance may help them in assessing and improving their abilities and capabilities to analyze, think critically, and even express ideas effectively. Herewith, even though success in licensure examinations depends more on the intellectual ability of the examinee, the effectiveness of teaching and performance of a teacher are measured (Cadient, 2011).

Therefore, above mentioned would truly prove that passing the Licensure Examination for Teachers (LET) is a necessity and a prerequisite to become a professional teacher. Since there is a mandate to take and pass this exam, it is evident that it plays a significance role not only to the teachers, but to the Philippine education system as a whole. 


\section{Chapter 2}

\section{PROCEDURES}

This chapter will provide and present a review of methods used to collect, to analyze, and to describe the research data for this study. With this, the following will be presented: study design, sampling techniques, research instrument and data gathering procedure, trustworthiness, and data analysis.

\section{Study Design}

According to Cresswell (1994) a qualitative study is a systematic process of understanding a human problem based on reporting detailed view of informants. This, study will be a qualitative research. Qualitative research can also gather the data directly and can acquire information from direct participants (Samuels, 2011). This interview will be used to consolidate and gather factual student's subjective experiences why did they fail in the licensure examination for teachers for the third $\left(3^{\text {rd }}\right)$ time. The process of interviewing will include recorders and other materials which will be transcribed in a paper. After transcribing, the respondents will sign on the lower right portion as a proof of authenticity and that the results gathered will not be revised, modified, and revamped. The qualitative case study is adjudged to be felicitous in our research because the goal of this research is to identify and discover the difficulties encountered by the licensure examination for teachers' examinee who failed three (3) times.

\section{Sampling Techniques}

In this research, the strategy which will be utilized is purposive sampling since the respondents are selected takers of the licensure examination for teachers'. The 
participants in this purposive sampling strategy are three (3) Bachelor of Secondary/ Elementary/ Special education students in The University of Mindanao, these three (3) examinees are known to take the licensure examination for teachers and failed. This Licensure Examination for Teachers (LET) or also known as Philippine Teachers Professionalization Act of 1994 is said to improve and to strengthen not just the teachers, but also the quality of education and the whole education system in general (Velasco, 2013). The Professional Regulation Commission (PRC) also added that the said examination will strengthen the supervision and regulation in teaching profession.

\section{Research Instruments}

In this case study, the research questions are well formulated by the researchers. The questions which will be used undergo first with the evaluation and validation process, conducted by the validators. After the validation, the questions will be pilot tested. The research instrument which will be utilized in this qualitative case study is interview questions and will be record for authenticity purposes. The questions in the interview are well formulated. In the research instrument, the questions are written and asked in English and they are allowed to use the language they are comfortable in order for them to freely express themselves without uncertainty.

\section{Data Gathering Procedure}

Data collection is the systematic way of gathering and measuring information which enables one to answer formulated research questions, test the hypotheses, and evaluate the outcomes. In this qualitative case study, data collection is chosen to actualize and achieve the purpose of the study and research question. In gathering the 
data, we will conduct an interview. Apart from the interview, the respondents will be informed and will be given a letter of consent that whatever information is gathered will be used only for the purpose of the study and be treated with utmost confidentiality. The said letter of agreement is to ensure that the respondents' privacy will be highly respected.

The three (3) participants in the interview are not forced by the researchers to partake in the said study. The researchers will use interview question as their data collection tool. In the interview, the respondents will answer the research questions provided by the researcher. Then they will use the language which they are comfortable. In case of comprehending problems, the researcher will translate the questions. The answers will be transcribed on paper and the researchers will identify the common theme in each questions and the overall theme. The whole duration of the interview will take 30-45 minutes and will be recorded with the respondents' approval. Lastly, the participants will sign on the lower part of the transcribed paper as a sign of authenticity.

\section{Trustworthiness}

As this qualitative case study research was conducted, the researchers presented letter to the three (3) participants. This letter contains the agreement that whatever information gathered will be used only for the purpose of the study and will be treated with utmost confidentiality. In order to establish trustworthiness, a research should have the credibility, transferability, dependability, and conformability. In terms of validity, the researchers are confident that this research is valid since they were able to identify correct operational measures for the concepts being studied (Pandey and Patnaik, 2014) which in this case is the interview since interview is very useful in terms of getting the 
background of the respondents and it can give in-depth information about the topic. (McNamara, 1999).

The researchers are confident in terms of the credibility of the result of this research since the three (3) participants are authentic Licensure Examination for Teachers (LET) examinee who failed in the exam. The researchers are aware of the ethical consideration in interviewing the participants. The respondents are able to express themselves without interruptions from the researchers. Lincon and Guba assert that it is the researchers' task to provide sufficient contextual information and background about the conducted research to provide transferability. To establish transferability, the researchers will provide a thick description; a term coined by Geertz (1973) which suggest that a research should not only have factual information but also rich commentary and interpretations. The researchers will provide specified and enriched detail, on the account of filed experiences. To establish dependability according to Lincoln and Guba a researcher should employ inquiry audit. In this research, we will have an outsider researcher who is not part of the research team to examine and observe both the process and product of the research study (Lincoln and Guba). This outsider researcher will describe in full detail how data was collected throughout the research, how categories were obtained, and how decisions were made throughout the research or inquiry. The point of doing this is to evaluate the accuracy and to evaluate whether or not the interpretations, conclusions and findings are supported by the collected data. To establish conformability, the researchers are confident that any form of biases is not tolerated and done throughout the inquiry. The way of asking questions were addressed with utmost respect. The researchers assure that whatever information gathered in this research are not fabricated and falsified. After transcribing their responses, the respondents reviewed and checked it and then 
they are asked to sign on the lower right portion if everything written is factual as a sign of authenticity. Lastly, the researchers assured the respondents that their identities will be confidential.

\section{Data Analysis}

The Statistics Canada (2015) defined data analysis as the process of developing answers to questions through the examination and interpretation of data. Hence, Johnson (2011) asserted that data analysis is the process of dividing all the data through the categories as a guide for the researchers. In general, Neuman (1997) defines data analysis as a search for patterns in data. Nevertheless, according to Statistics Canada (2015) data analysis plays a vital role for comprehending and understanding the results that the researchers accumulated from the surveys, interviews, and administrative sources. In this qualitative case study, the data analysis will show the themes from the data gathering procedure. Then, it will be analyzed to get the overall theme or the common denominator in each case. Once the overall theme will be identified, then it will be a subject for further analysis which will be discussed in the next chapter. This will then give the researchers an in-depth idea about the reasons and struggles they faced that lead to their failure in the licensure examination for teacher for the third time.

Now, in the process of identifying the overall theme, the researchers will carefully analyze the answers of each respondents per item. They will find out what is common to the three (3) respondents. With this qualitative case study research, the graduates of The University of Mindanao will be aware of the experience which had happened in the three (3) examinees. The aspiring future teachers will now learn how to either prevent or overcome this problem. 


\section{Role of the Researcher}

The researchers play a vital role in this case study since they will be the one who will put into action and find the solution to the problem in this research. The researchers will be the one to gather data and conduct the interview to have a factual and in depth information about the respondents story and experience. Furthermore, the researchers will provide a thick description of the facts and context. They will provide probe questions which will dig deeper to coincide with the research questions. They will record and transcribe the answer of the respondents and will find the central theme of the case study.

\section{Ethical Consideration}

According to the Grand Canyon University (2016), ethical consideration plays a critical and important role in the field of research. It is for the reason that ethical consideration prevents fabrication and falsification of data and information and it promotes the quest in search of knowledge and truth which is the main goal of the research.

Apart from the quest of truth and knowledge, the researchers also value the rights of the respondents. The respondents were fully aware and informed about nature and how the project will be done. They know how the data and results will be shared and used. Their privacy and the confidentiality of the results will be treated with utmost respect and will only be utilized for research purposes. The participants were truly voluntary and do not feel any pressure to be involved in the research. Lastly, there were no minors involved and no right was violated throughout the whole inquiry and research. 
The respondent's right to privacy will be respected and observed. The participants will be assured that the data that was gathered from them will be kept confidential. Their identities and any personal information will remain anonymous. The researchers are confident that the data collected were reliable and authentic. The researchers also had the obligation to ensure the safety and security of the participants. The participants were free from any form of harm and danger including physical, social, and emotional harm. The participants were not embarrassed and were asked square and fair. The research tools were free from biases and subjectivity.

The researchers were able to address all the three (3) ethical consideration. The respondents were given informed consent. Their right to privacy was very much respected and observed. They were protected to any form of harm (Grand Canyon University, 2016). All the respondents were fully informed of the process and they were not forced. The researchers were committed to the participants that all the information gathered will be used solely for research purposes only. Furthermore, the data and information gathered were authentic, reliable, and trustworthy. Everything that was gathered was free from fabrication and falsification. 


\section{Chapter 3}

\section{Findings and Analysis of Themes}

This chapter shows findings in our qualitative research why did the takers fail in the licensure examination for teachers. This section includes the interview findings and analysis.

\section{Interview Findings}

This qualitative study was anchored with one research question "What do you think were the major reasons or factors why you failed the Licensure Examination for Teachers?" Several factors emerged during the course of our interview. Each finding is presented and explained in this section. The takers shared their experience about the factors affecting their performance throughout their licensure examination endeavor.

\section{Participants}

Taker

Age

Sex

Specialization Num. of Takes

$\begin{array}{lllll}\text { Lawaan } & 37 & \text { F } & \text { Soc Stud /Earner } & 1 \text { (present) } \\ \text { Molave } & 22 & \text { F } & \text { Generalist } & 1 \text { (present) } \\ \text { Narra } & 28 & \text { M } & \text { English } & 2\end{array}$

These are our participants whom we interviewed for our study. We did not include their personal information to protect them and as a sign of respect with our agreement. 


\section{Analysis of Themes}

There were 3 participants in our qualitative study. All of them shared their experience and answer in each of the question. There were several factors that emerged during our interview. The most common about the three respondents was that they all did not enroll themselves in a review center. Below were the common denominators why they failed in the licensure examination.

\section{Physical Factor}

During their examination, both Molave and Narra revealed that they were both not feeling well. Both of them suffered fever. However, Narra also suffered cough "Murag kuan kanang kalintura, oo pero dili ingon nga grabe. syempre" (Like I had a fever, yes but it was not severe) said Molave. Furthermore, Narra also revealed during the interview that "My health? Actually, payatot jud kaayo ko ato , malnourished. Sige ko atog kalintura, ubo ubo kay na stress napod ba tungod sa pag think nga hapit na ang exam" (My health? Actually, I was really skinny that time, malnourished. I always got fever, cough because I was really stress because I think the exam is already near). Moreover, Narra and Lawaan agreed that they both lack in terms of sleep. Lawaan revealed that "Nakatulog ko atung exam" (I slept during the exam).

\section{Environmental Factor}

All of the re-takers revealed that the environment factor affected their performance in their exams. In fact, Molave shared that "Ma feel nako nga sa ano sa JMC feel nako dili jud ka concentrate kay saba kayo ang eroplano didto nga nagtuyok tuyok" (I can feel that in JMC I feel that I cannot concentrate because the airplane 
keeps on rotating and it's noisy). Narra also added that "Actually it is not conducive saba sya,dili lang man kay ako ang tao na saba pag abot nako ang music gipaandar na." (Actually, it is not conducive, it's so noisy because I am not the only one and when I got home the music is on). Narra also included that the room was also really hot.

Psychological

In the psychological aspect, both Molave and Narra revealed that they were really over confident before taking the licensure examination for teachers but they still failed in the exam. In fact, Narra also revealed that "First take nako actually self review rajud before ko nag take sa LET and over confident na kaayo ko nga feel nko makapasar ko sa LET, that's why." (The first time I take, I just did self review before I took the LET and I was over confident that I feel that I can pass the LET, that's why). On the other hand, Molave also revealed the source of her confidence "Sa akoa kay mag review man gud mi dra sa UM ingon nila naa daw manggawas pero pag abot sa exam wala man" (For me it's because we are reviewing in the UM. They say, it will come out but in the exam there was none.)

\section{Mental Factor}

During the course of our interview endeavor, we found out that both Molave and Lawaan suffered mental block during the exam. In addition, Lawaan share her experience that "mental block bisan unsaon nimo ug inhale ug exhale nawala jud ka sa imong mind" (Mental block was also present, even if I inhale and exhale, I was lost in my mind). Both of them also revealed that they found ambiguous terms that hinder them to perform at their best. They also agreed and shared that the long questions and choices were problem especially the deep words. In fact, Lawaan revealed that "Tag as ang questions tag as jud ang choices ang prof.ed jud ang pinaka lisod. Sometimes, 
naa jud sya. take time man gud sya,then ano pag kanang dili nimo familiar ang word kanang lalom kayo sya murag mag take time pod kag analyze kong unsa kahay meaning ato makaafect jud sya". (The questions and choices were long and the professional education was the most difficult. Sometimes, there are (ambiguous terms) it will really take time if you are not familiar with the words. The deep words would really take time to analyze if what's the meaning and it would really affect.")

\section{Preparedness}

During the whole course of our interview, we found out that the preparedness of the takers would really make or break them. Both Narra and Lawaan were honest enough to share that they lack in terms of preparedness and study because they were both employed during their licensure examination for teachers endeavor. They shared that if you will not prepare and study you will really fail. Although, this is contradictory to the part of Molave because according to her she really prepared and have confidence in terms of her readiness. Nevertheless, Narra releaved to us that one of the major reason why he failed was "First kay lack of time, study, reviewer". In addition, Lawaan also responded that "Sa akoa mismo sa sarili murag kanag dawat na nako kay dili jud ko prepared dili pod jud ko equip ky kulang jud ko ug study" (I know in myself that I accepted the result because I was not prepared and I was not equipped because I lack study). 


\section{Chapter 4}

\section{Discussion}

In this chapter, each theme will be further discussed. This study is anchored on the task in distinguishing the reasons why some of the licensure examination for teachers' takers failed in the said exam.

Throughout our research endeavor, five (5) themes emerged after the interview was conducted. Included in the themes were physical factor, environmental factor, psychological factor, mental factor, and preparedness factor. All of these factors or theme contributed to their low performance in the duly concluded exam. We found out that most of the respondents were not feeling well during the time they take the exam. They had fever and cough. They also did not get enough sleep because they studied and prepared for the upcoming licensure examination for teachers. According to the authentic respondents, it really affected their performance in a negative way. Another factor that affected them to perform at their best was the environmental factor. They admit that they cannot concentrate well because when they were preparing for the exam, their environment specifically their home was really noisy. The other respondent also said that during their exam the environment was not that friendly because there was so much noise caused by the airplane since the school in which she was assigned was near in the airport. The chair was another problem because it keeps on moving and because of that she was distracted. Accordingly, this phenomenon affected them in a negative way. Moreover, the psychological aspect was also another factor why they failed. Two of the respondents shared about what they feel during their exam. They were both confident that they can pass the exam. The other respondent shared that she was confident because she review in the UM and she attended regularly. 
She also expressed that she was really studying. The other one revealed that his parents had a high hope and trust that he can pass the exam that is why he did not enroll himself in a review center. What he did was self study and he gathered reviewers from the University of Mindanao. In addition, the mental factor also emerged as a reason why they failed in the licensure exam. They expressed that they had suffered mental block during their examination. Because of this, they had a hard time in answering. Two of them also agreed that there were ambiguous terminologies that hinder their comprehension because of this ambiguity they cannot analyze and decipher the meaning of the words. In addition, the very long questions and choices were also a reason why they had a hard time. The last theme was their preparedness; all of them responded that they did not enroll in any review center except for the other on who attended regularly the review in the University of Mindanao. Two of them shared that they do not have enough time to study because they are both employed. These are the factors or reasons why they failed in the licensure examination for teachers.

\section{Conclusion}

The result in this research is very beneficial to the re-takers, aspirant teachers, professors, administrators, and host school. The results in this research is very significant to the re-takers and aspirant teachers because they will now fully informed about the reasons that may hinder them to perform at their best since the results gathered in this research came from authentic and reliable sources. In addition, they will also learn that sometimes they should not be over confident and take the licensure examination as a very easy task. They can now think a head of future responses to these circumstances. For the teachers, the teacher will now have a clearer perspective that one of the factors why students failed was because of the very deep terminologies, very long questions and choices. With that, the teacher can now employ a variety of 
strategy as how to solve this difficulty. For the administrators and host school of the licensure examination, they will now be learned that the environment plays a big role in the performance of the takers. With that being said, hopefully they will make way to solve problems such as moving chairs, classroom which were not conducive, noisy environment, and the likes.

If you failed in the licensure examination, you are automatically equated as "low performing student". However, in this research there are several factors that can affect as to why the takers of the licensure examination for teachers failed such as physical factor, environmental factor, psychological factor, mental factor, and preparedness. We conclude that to have the best result in the licensure examination you must not have any problems or issues in this aspect.

\section{Recommendation}

For future research, the researchers would like recommend the following:

1. For the other researchers who wanted to pursue this research, they should not limit the number of respondents to three (3) to ensure reliability of the results. We would also like to recommend having a respondent from each specialization.

2. For the teachers, we would like to recommend having the result as a basis for their strategies to prepare the takers for the licensure examination for teachers. We would like to recommend that they will help the aspirant teachers in terms of their difficulty when it comes to very deep terminologies, very long questions and choices.

3. For the administrators, we would like to recommend that they should do an action to solve problems about the environment. Since the learning environment plays a big role in the performance of the takers. We would like to recommend the problems when 
it comes to the chairs and the electric fans since according to the respondents it can affect their performance.

4. For the aspirant teachers and takers, we would like to recommend that they should make use of the result why some of the takers failed. In addition, we would like to recommend that as early as now they should now find alternative problems with the factors that led to the failure of some of the takers. 


\section{References}

Achebe, C. (2001). Multi-modal counselling for examination failure in a Nigerian university: a case-study. Journal of African Studies, 9, 187-193.1

Alipio, M. (2020). Predicting Academic Performance of College Freshmen in the Philippines using Psychological Variables and Expectancy-Value Beliefs to Outcomes-Based Education: A Path Analysis. EdArXiv. https://doi.org/10.35542/osf.io/pra6z

Armstrong, T., (2009). Multiple Intelligences in the Classroom (3rd Ed.). 242.pp

Balagtas, M., and Gerundro, M.(2014). Exploring formula for success in teacher's licensure examination in the Philippines. Educational Measurement Review. (5) 104-117. Retrieved from hhtp://www.ejournals.phindex.php

Burgess, R. G. (Ed.). (1989). The ethics of educational research (Vol. 8). Psychology Press.

Burman, M. E., \& Kleinsasser, A. M. (2004). Ethical guidelines for use of student work: Moving from teaching's invisibility to inquiry's visibility in the scholarship of teaching and learning. The Journal of General Education, 53(1), 59-79.

Cadient, A.M. 'Predictors of Performance of Eastern Visayas State University Ormoc City Campus (EVSU-OCC) Graduates in the Licensure examination for Teachers"'. Master Thesis. Eastern Visayas State University Graduates School, Tacloban City, 2011.

CHED (1999). CHED Memorandum Order No. 11, s.of 1999. Revised Policies and Standards for the Teacher Education, 125.pp

Cochran, K. F. (2010, January 14). Pedagogical Content Knowledge: Teachers' Integration of Subject Matter, Pedagogy, Students, and Learning Environments. Retrieved from HTTP://www.narst.org/publications/research/pck.cfm

Cresswell, John W. "Research Design: Qualitative \& Quantitative Approaches'. 4th ed. California: SAGE Publication.

Ditan (2008). Teachers and Learners' Knowledge, Attitude and Challenges Experienced in Relation to Large Class: Inputs to Policy. (2013). The Normal LIghts, 7, 37-63. Retrieved from https://www.pnu.edu.ph/wpcontent/uploads/2014/08/Normal-Lights-Vol_7_no2-2013_WEB_Ver.pdf.

Faltado, R., (2014). Correlates of performance in the licensure examination of selected public and private teacher Education institutions. International Journal of Education and Research. 2(8) 167-175. Retrieved from http://ijern.com/journal/2014/ August-2014/16.pdf

Garcia, G., (2013). Academic performance as department to pass the licensure examinations for teachers. International Peer Reviewed Journal, JPAIR. Retrieved from http://www.philair.ph/publication/index.php/ir/article/view/258 
Harper et.al (2004, October). Misconceptions About Teaching English-language Learners. Retrieved from https://www.google.com/search?client=firefox-bab\&noj $=1 \& q=($ Harper, Candice and de Jong, 2004)\&spell=1\&sa=X\&ved=0ahUKEwi53bXZlsjSAhUDG5QKHSyeAFEQvw UIGCgA\&biw=1366\&bih=657\&gfe_rd=cr\&ei=AaTAWJ-6HrCM8Qf5sJaQDw

History of Licensure Examination for Teachers: A Short Review. (2013, July 17). Retrieved from http://teaching-principles.com/2013/07/history-of-licensureexamination-for.html

Montemayor, E.S.,C. C Roxas, and V.L Panayon. (2009). Mock examination: its influence on performance in the licensure examination for teachers. University of Cordilleras Research Journal, 1(3), 1-11. Retrieved from http://www.eisrjc.com/documents/Mock_Examination_1325666288.pdf

Ojumo, B. (2016, May 16). TOP 9 Reasons why students fail exam. Retrieved from https://passnownow.com/top-9-reasons-why-students-fail-exams/

Ramos (2013). LET as Predictor of Teaching Performance: The Case of PNU Graduates across Disciplines . The Normal LIghts, 19-37. Retrieved from https://www.pnu.edu.ph/wp-content/uploads/2014/08/Normal-LightsVol_7_no2-2013_WEB_Ver.pdf

Retrieved from http://www.prc.gov.ph/prb/default.aspx?id=38\&content=223

Retrieved 2016, from http://www.prcboard.com/2016/09/Results-September-2016LET-Teachers-Board-Exam-Elementary-Secondary.html

Retrieved from http://nlpdl.nlp.gov.ph:81/CH01/MO/1999/CH0MO0011s1999.pdf

Shulman, L. S. (1986). Those who understand: Knowledge growth in teaching. Educational Researcher, 15(4), 4-14.

Spring. (1997). The Case Study as a Research Method. Retrieved from https://www.ischool.utexas.edu/ ssoy/usesusers/1391d1b.htm

Tarun, I, Gearado, B. and Tanguiling, B. (2014). Generating licensure examination performance models using PART and TRIP classifies: A Pata Mining Application in Education. International Journal Computer and Communication Engineering. 3(3) 203-238. Retrieved from http://www.ijcce.org/papers/320-CS 2004.pdf 